\title{
Patient Compliance with Exercise: Different Theoretical Approaches to Short-Term and Long-Term Compliance*
}

\author{
E.M. Sluijs, MSc and J.J. Knibbe, MSc \\ Netherlunds Institute of Primary Health Care, Utrecht (The Netherlands) \\ (Received July 19th, 1990) \\ (Accepted October 29th, 1990)
}

\begin{abstract}
Compliance with exercise regimens is difficult to obtain as is compliance with other medical regimens. In analyzing noncompliance, two problems exist: (1) current theories only partly explain patients' noncompliance; (2) health care providers seldom act according to the recommendations derived from research findings. These problems may be due in part to great differences in types of compliance behavior. A significant difference exists between short-term supervised compliance and long-term nonsupervised compliance. Therefore different theoretical and practical approaches may be needed depending on the specific compliance behavior in question. Analysis of compliance with exercise regimens indicates that interventions based on behavioral theory are adequate for short-term compliance, whereas a self-regulation approach can be useful in long-term compliance. As a logical consequence, the health care provider should be able to act differently, according to the type of compliance needed. The practical implications for exercise regimens in physical therapy practice are discussed in detail.
\end{abstract}

*This paper was adapted from a requirement for a PhD-thesis on Patient Education in Physical Therapy funded by the Praeventiefonds. This research program is still in progress.
Keywords: Short-term compliance; Long-term compliance; Theoretical approach; Exercise compliance; Physical therapy.

\section{Introduction}

A multitude of research papers on patient compliance has provided us with valuable insights into the complicated nature of compliance. In the past few decades several important theoretical models concerning compliance emerged, proposing solutions for the compliance problem [1,2] and research has resulted in the discovery of over 200 factors related to compliance [3]. Nevertheless, it appears that these separate theories and models only partly account for the differences in compliance. The explained difference is often small and the correlations weak or even contradictory [1-4]. Compliance problems differ in nature, however [5,6]. As a consequence, different theoretical approaches may be appropriate for different types of (compliance) behavior.

Besides the theoretical problem, a practical problem exists. It is disappointing that health care providers seldom act according to valuable recommendations derived from research [7,8]. As Bartlett [9] states: "There is 
a 15-year lag between theory and practice." Although research advances rapidly, practice patterns are registering only modest improvements. This discrepancy could be related to the inconsistency of research findings. Health care providers are often confronted with recommendations from researchers that seem ad hoc, or diverse and fragmentary [10]. Providers need guidelines tailored to the specific compliance behavior desired in their health care setting. Providing the health professional with insight into the mechanisms underlying the recommendations and selecting the most powerful, yet simply applicable strategies may facilitate acceptance and practice of the recommendations.

We will argue that it is essential to specify the characteristics of the desired type of compliance. This enables an optimal choice of a theoretical model or combination of theories. From this selection practical recommendations for the health care provider can be deduced, which theoretically speaking, have a maximum potential for attaining compliance.

First compliance behavior will be analyzed. An important way in which compliance behaviors differ is the length of the period in which compliance needs to be maintained. The distinction between long-term and shortterm compliance has implications for the choice of a theoretical approach. It is also meaningful to distinguish between compliance with curative regimens and compliance with preventive measures. Distinguishing different forms of compliance has been done by various authors/researchers [1-3]. Studies focus on compliance behavior in specific diseases, specific groups of patients or on different treatment regimens [11]. Distinguishing shortterm compliance from long-term compliance has also been done [12-14], mostly resulting in the conclusion that long-term compliance is far more difficult to obtain than short-term compliance $[13,15,16]$. Although a search for new theories is proposed [17], it may be promising to take selective advantage of existing theories based on a clear distinction between short-term and long-term compliance.

Secondly, we will argue that short-term compliance is best achieved by using the basic principles of a behavioral approach, whereas the self-regulation perspective could be useful in achieving long-term compliance, with different stresses depending on the curative or

Fig. 1. Three-step approach for compliance.

\begin{tabular}{|lll|}
\hline COMPLIANCE BEHAVIOR & THEORETICAL APPROACH & $\begin{array}{l}\text { IMPLICATIONS } \\
\text { FOR PROVIDER }\end{array}$ \\
SHORT-TERM COMPLIANCE & BEHAVIORAL APPROACH & RECOMMENDATIONS \\
curative - preventive & & \\
LONG-TERM COMPLIANCE & SELF-REGULATION MODEL & RECOMMENDATIONS \\
curative - preventive & & \\
\hline
\end{tabular}


preventive orientation. These propositions will be supported by logical and empirical cvidence.

Finally, we will explain how these different theoretical approaches implicate a selective use of the various recommendations given a specific health care setting. As an example we will work out the three steps for compliance with exercise regimens in physical therapy (Fig. 1), as compliance is a relevant topic in physical therapy [18-21].

\section{Exercise compliance in physical therapy}

In the Netherlands over $10 \%$ of the population is treated yearly by physical therapists [22,23]. Most disorders concern impairments and handicaps of the locomotor system; neck, shoulder and back pain account for $50 \%$. Around $30 \%$ of the disorders appear to be chronic and there is a high recurrence rate [22-24]. An essential part of physical therapy is instructing patients in how to do exercises at home and advising them of the right behavior in order to recover [20]. This is particularly true because definitive cure is frequently impossible, and secondary prevention often involves behavioral change [23,25-27].

The exact amount of patient compliance with these regimens is not known. It is remarkable that measures of patient compliance are frequently absent in research reports on exercise programs, although program effects may depend largely on the amount of patient compliance [28-32]. In addition, differences in the definition of compliance and in the observed follow-up period render the interpretation of result difficult.

Nevertheless, some conclusions can be drawn. Compliance with exercise regimens ranges from 30 to $57 \%$ [33-40] and rates of compliance drop as time passes [27,41-44]. The greatest drop is associated with the moment of discharge. Physical therapists are aware of this drop in compliance. They estimate that on average $64 \%$ of their patients complied with exercise prescription during the treatment period, while only $23 \%$ continued to do so after treatment had stopped [45]. Thus, physical therapists do not seem to overestimate their patients' compliance level, as physicians appear to do [46]. Based on these findings it seems worthwhile to enhance compliance in physical therapy.

\section{Analyzing compliance behavior in physical therapy}

The initial step in approaching compliance problems is to define clearly the type of compliance behavior involved. Several components of treatment which require compliance can be distinguished, such as entering treatment, keeping appointments and behavioral change. The last of them is the main issue in physical therapy and thus is the focus of this article.

Physical therapy involves changing behavior in at least three different respects: first, physical therapists instruct people to perform and master certain motor skills or techniques of movement. Examples of motor skills are muscle-strengthening exercises, exercises to change one's posture, or breathing techniques. The second step is to integrate this movement-behavior into daily life $[21,47,48]$. Some exercise programs are only effective if performed daily, patients need to maintain the regimens after symptoms have disappeared in order to prevent recurrence of the illness [20,48]. Thirdly, besides teaching exercises, physical therapists offer their patients other kinds of health advice with curative or preventive purposes [45], for instance, changing one's mattress, wearing better shoes, or taking more time to relax. In all these instances success of treatment and prevention of further problems largely depend on patient compliance [49-51].

Short-term supervised and long-term nonsupervised compliance

The current definitions of short-term com- 
pliance and long-term compliance, based only on a certain period of time are confusing. A same period can have different significance in different situations. For example, long-term compliance, measured 2 years after the cessation of a program has different significance than a 2-year follow-up measure taken immediately after cessation of a program lasting 2 years, because supervision is an essential element in compliance [33,52-54].

Therefore, our definitions of short-term and long-term compliance differ from the quantitative measures. We define short-term compliance as compliance with the regimen within the period of treatment, which is usually a short and limited period. It can also be called supervised compliance, because contact with the health care provider within this period is an important component. It means that the provider has more or less direct perception, influence and control over the process. If short-term compliance is required, physical therapists can optimally employ the favorable conditions the therapy setting offers [26,55-57]. In the Netherlands the treatment procedure usually consists of frequent (twice a week) personal contacts for 20 to $30 \mathrm{~min}$, spread over a relatively long period of time ( 6 weeks on average) [58]. This means that the treatment program can be built up gradually, step by step $[21,56,59]$.

We define long-term compliance as compliance after the treatment period. From the moment treatment is stopped, the influence of the health care provider is minimal or absent. Indeed, in this phase compliance behavior must literally be self-regulatory in nature in order to be maintained [60]. This is often necessary in treatments with a preventive orientation, which brings us to the second subdivision of compliance behavior: the curative or preventive orientation of treatment [61].

\section{Curative and preventive orientation of physical therapy}

As long as the distinction between curative and preventive treatment is simply seen as a question of two clear definitions, there is a considerable amount of overlap. For example, advice to sit with a straight back facing a computer monitor at the right height is both a curative and a preventive piece of advice. Nevertheless, significant differences exist.

Curative measures aim at success in the shortest time possible. When the goal is reached, namely the absence of certain symptoms or signs, curative treatment can be stopped. The product of curative physical therapy is clear, namely recovery, and it can be evaluated likewise, both by the patient and by the provider. If treatment is continued, its aims can be oriented or reoriented towards prevention [20]. Prevention, in its most ideal form, is directed at infinity, meaning the product itself is in fact never reached and its goal is in essence a process instead of a product. The clear evaluation of success or failure of curative treatment contrasts with the more subtle evaluation of preventive measures. Neither the provider, nor the patient can in any stage be confident about whether the chosen course of prevention is the ultimate and most successful one. Preventive measures may even be a success when the symptoms recur at a slower rate. This can be confusing to patients and could influence compliance behavior [11].

These differences both in the orientation in time and in the possibility of evaluating success or failure have implications for the way compliance can be reached with curative measures, on the one hand, and preventive measures on the other.

On the basis of these distinctions in compliance behavior we will analyze why the behavioral approach seems to be particularly useful in short-term compliance, with different accents in curative and preventive measures. After that, the same procedure will be followed for long-term compliance. For the sake of clarity the differences between the approaches are stressed. 
The behavioral approach in short-term compliance

\section{Introduction}

The contemporary behavioral approach fits within social learning theory, but its main principles are derived from operant learning theory $[62,63]$. Conventional learning theory is based on the assumption that behavior is determined by its antecedents and its consequences. This means that behavior is influenced by stimuli that elicit behavior, and by feedback or positive consequences that reinforce behavior. Stimuli are objects or situations that elicit a response. For example, seeing my sportshoes reminds me of jogging; the onset of a headache reminds me of doing relaxation exercises. Stimuli act as a kind of reminder that draws the individual's attention to his or her behavior. Any kind of environmental or social condition can serve such a cueing function. So, if behavior change is desired, one has to seek conditions that support the desired behavior and change or avoid conditions evoking undesired behavior.

According to the theory, stimuli are necessary but not sufficient conditions for behavior change: the reinforcements or rewards that follow the behavior make sure that behavior will be repeated and sustained. For example, the fine feeling after jogging motivates me to jog again; the disappearance of my headache make me sustain the relaxation exercises. If reinforcements are withdrawn, the behavior gradually disappears, or, in terms of the theory, is extinguished.

This latter principle is the reason why a behavioral theory is often successful in attaining short-term compliance - as is convincingly demonstrated by research findings [64] but usually fails to achieve long-term compliance [65]. As long as the intervention continues and the provider can stimulate or reinforce desired behavior, compliance is likely to occur. When the provider stops the regular treatment, and its associated reinforcing feedback, behavior is likely to drop to the pretreatment level. This is exactly what the theory predicts.

This behavioral approach can be criticized in two ways. Many authors point at the limitations of behavioral theory because of its failure to attain long-term compliance [66]. However, they tend to overlook that the majority of medical treatments require only short-term compliance. In all such cases a behavioral approach appears to be adequate.

The second kind of criticism concerns resistance against a rather mechanistic view of behavior in the original learning theory, denying cognitive processes in learning [67]. This was certainly true for the original applications of the theory, mainly based on animal experiments, but does not apply to the contemporary adaptations derived from social learning theory. Nowadays it is acknowledged that it is the individual's interpretation and perception of behavior-sequences that is crucial. Only individuals themselves can detect which objects or situations in their daily living can be meaningful reminders. The same holds true for reinforcements: identical rewards may motivate one person but be meaningless for someone else. So, a behavioral approach cannot succeed without active patient participation, nor without a treatment that is tailored for the patient's situation and preferences.

\section{Behavioral approach in physical therapy practice}

Applying the behavioral approach in physical therapy does not mean applying a form of psychotherapy. We will concentrate on simple, yet powerful principles of behavior change $[6,64]$ requiring a minimum of extra skills or time $[13,68,69]$. If physical therapists wish patients to act according to instructions and advice given, three topics deserve attention: behavior, stimuli and reinforcements.

Firstly, physical therapists instruct the pa- 
tient in what to do and how to exercise. Usually they supply their instructions with modeling and guided performance to make patients acquire the necessary skills to exercise. If a complex behavior is involved, as is often the case, the behavioral principle of shaping can be used, which means that skills are acquired step by step and divided into less complex units [70,71].

Secondly, if the patient knows and accepts what to do and thus has the basic intention to comply, the next step implies the search for the most appropriate circumstances or cues in the patient's daily routine that can function as reminders. This enables the behavior to become part of daily routines [67,71,72]. For example, patients can put a sticker on the telephone that reminds them of doing pelvicfloor exercises each time the telephone rings. Or, one can make it a custom to do the neckshoulder exercises at the bathroom, as one therapist advised his patients; entering the bathroom became a cue for the patient to exercise. Patients should understand and accept the function of reminders. Therapists must explain that they are aids in performing the desired behavior [60]. The discovery of adequatc reminders depends on active participation by the patients because they know their daily routines and personal lifestyle best. Physical therapists can assist the patient in discovering and using cues as aide-mémoires.

Thirdly, there is a need to reinforce desired behavior, for which there are several options $[20,73]$. The physical therapist can give attention or positive feedback on progress, show appreciation of the patient's efforts and explain that treatment success depends on it. Therapists can also praise the actual smooth performance of the exercises [20,74]. Fortunately, some exercises can be intrinsically rewarding: stretching exercises may instantly relieve backpain; intense exercising may give a satisfied relaxed feeling afterwards. Finally, support from relatives can be rewarding as well. Attending patients to rewarding effects can enhance short-term compliance $[34,74,75]$.
In order to reward adequately the provider has to know if the patient has actually performed the desired behavior [21,39,44]. Physical therapists have two ways of assessing patients' compliance. First, they can simply ask the patients whether or not they have complied. Becker states that nonthreatening questioning makes reliable answers most likely [11]. In addition, physical therapists can request performance of the exercises and judge the progress and performance [75]. If the patient is considered noncompliant, one can, according to the theory, intervene in all three steps: behavior, stimuli and reinforcements.

If performance of the behavior itself causes difficulties to the patient, substituting a more tailored behavior may remove the barriers $[71,76]$. It may be sufficient to proceed at a slower pace or to take a small step back in the treatment process if symptoms or pain limit compliance. If the reminders to do the exercises appear to be inadequate, the therapist can help the patient to seek other reminders. If the rewards are not sufficiently appealing, one can explain that positive results are not always immediately visible, or one can search for more motivating alternatives. In this search the information gathercd from the patient's perspective is essential [77]. Therefore, there is a need for a good relationship and an open dialogue with the patient $[36,78-80]$.

\section{Differences between curative and preventive measures}

The behavioral approach slightly differs in curative and preventive measures. In curative treatment symptoms and pain may facilitate the behavioral approach because they can act as reminders while relief of symptoms and pain can be rewards, as was noted. When symptoms are absent, as in the case of preventive measures, other rewarding sources can be found. An example of short-term compliance in a pre-operative breathing exercise program which is aimed at preventing post-operative respiratory distress may illustrate this. Although symptoms are absent, progress in mastering the technique can be visualized on 
a chart or the patients can learn to experience and evaluate their own progress [74]. The progress can give them a sense of active control over their health, which could be rewarding when facing major chest surgery.

\section{Self-regulation theory in long-term compliance}

These direct options, relying mainly on the supervising role of the provider and on the presence of rewarding effects, are often lacking when long-term compliance is necessary. The provider is absent along with the positive feedback and when recovery has set in, the intrinsic rewards of pain relief dissappear and symptoms no longer trigger the exercises. An additional problem emerges because relapse into the previous behavior pattern often does not provoke any symptoms. The possibility of prolongating the effect through regular recall visits or continued supervision or support [41] could be helpful, but dependence on health care is the consequence. In some cases totally different solutions can be found, such as ergonomic adaptations, not requiring longterm compliance $[81,82]^{*}$. However, selfregulation of the behavior is often the optimum goal, indicating that a different theoretical approach is required.

\section{The main principles of the self-regulation theory}

Because long-term compliance is hard to at-

\footnotetext{
* Recognising the difficulty of reaching long-term compliance, it must be stated that there are other options available, especially in physical therapy [25], by avoiding the compliance problem altogether. Simpler and even permanent solutions may not require behavioral change, such as is suggested for example by Haynes [81]. He proposes to invest in the search for medication which is convenient to take and, once taken, has long lasting effects. In physical therapy such simple solutions are often available. Reducing the physical load on the patient, for example through ergonomic adaptations at home, instead of training his muscle power, could have a permanent preventive effect [82]. This requires minimal effort from the side of the patient and it certainly avoids the question of reaching compliance with an exercise program for the rest of his life. Besides, it promotes patients' independence of health care. The value of acting along this preventive route seems to be underestimated by physical therapists [25].
}

tain without prolonged supervision [14], Leventhal proposed a new approach [66]. He constructed the theory of self-regulation or self-control, in which he integrates effective concepts from other theories that have proved their efficacy $[66,83]$. Such concepts are derived from the health belief model [84], selfefficacy [85], self-management [67] and also the behavioral approach.

Self-regulation theory reflects a common sense way of dealing with health and illness: patients are considered active agents, choosing their own goals, which are mainly determined by their perceptions of the illness. They select responses or behavior to reach those goals and evaluate their progress in goalattainment. An everyday example may illustrate this basic mechanism: John has a low back pain. In his perception it is caused by a cold draught and the wet autumn weather, although at the back of his mind he knows that stress caused by his work could also influence it. His aim is to be free of back pain, so he wears an extra sweater, takes hot showers and avoids a draught. If the back pain disappears, he decides that his perception and way of dealing with the problem have been correct. If there is not any improvement, he may change his perception to the stress-perspective, he may change his coping strategy, or he may change both. To utilize and enhance this mechanism - according to Leventhal - three aspects deserve attention: (1) perception or representation of the illness, (2) coping with the illness, and (3) appraisal of the outcomes.

Representation of the illness. Experiencing symptoms or illnesses, people seek labels or diagnoses to explain and understand them. This perception of the illness is based on current symptoms, on earlier experiences with illness and on personal views of health and illness originating from social and cultural influences. Altogether these elements form the patient's representation of the illness, which can be highly individual. Research on the health belief model stresses the importance of 
these individual perceptions [37]. Knowing these representations is very important to the provider because the way patients cope, depends on them.

Coping with the illness. In coping with an ilIness, patients will take those actions they personally consider to be adequate. Patients have their own expectations, preferences and goals, mainly based on earlier experiences. If the treatment plan and prescriptions do not fit into this existing scheme, long-term compliance is unlikely [86]. Coping also depends on the patients' repertoire of behavior skills and sense of effectiveness. The latter is essential in the phase of appraisal.

Appraisal. Self-regulation theory implies that patients learn to evaluate the sequence of representation, coping and outcome. Essential in the theory is the fact that evaluation occurs in such a way that it enhances the patients' feelings of self-esteem or sense of effectance [85]: disappointing outcomes should not be seen as failures but as signs to distinguish ineffective from effective coping tactics. For example, when John's backpain remains after hot showers and warm clothes, he assumes that not the draught but distress was the cause and, according to it, he changes his coping. In doing so, he perceives himself as being able to distinguish suitable from unsuitable representations and adequate from inadequate coping. According to the selfregulation theory, patients should get a view of themselves as observers or experimenters whose goal is to test and accept or reject specific acting.

The main principles described above merely concern the cognitive level of dealing with ilIness. The theory states that a parallel and equally important process can be seen at an emotional level [85]. The embarrassment or worries caused by the onset of symptoms may distort patients' perception of the identity and cause of the illness. Symptoms may even be ignored because they are too threatening to face. In the second phase of coping with illness, feelings of frustration or even guilt may arise: health behavior may require changes in lifestyle and conflicting goals can exist between health behavior and other priorities in life like social engagements or ambitious jobs. In the third phase of appraisal the outcomes may be disappointing and may cause anxiety and anger [87]. Furthermore, if coping fails, the patient may encounter feelings of hopelessness or ineffectiveness and such feelings inhibit further trials [85]. These processes are closely interrelated to the cognitive one and long-term compliance is determined by both, indicating intervention at both levels must be taken into consideration.

Before turning to the practical implications of this approach for health care providers, one remark has to be made. Strictly speaking, the term compliance is not correct in the view of self-regulation theory. Instead of following the exact prescriptions of the providers, patients seek, discover and select coping behaviors that suit them [88]. The role of the provider is to support and stimulate the patients, teaching them the necessary skills, and transmitting knowledge as an expert enabling patients to choose their own appropriate solutions [89-91].

\section{Self-regulation principles in physical therapy practice}

Although self-regulation theory is not clearly made operational for use in health care delivery, its significance is recognized for the field of exercise adherence. We will try to make these elaborations for long-term compliance in physical therapy.

Representation. To adjust treatment to the patient's frame of reference the therapist must explore the patient's representation of the illness. If patients' perceptions and ideas conflict with medical knowledge, it is necessary to correct them. For example, to the patient who said "My back is crooked, I often feel it cracking" must be explained that, as a rule 
cracking sounds are harmless and not alarming. Patients who focus on minor deviations on the X-ray and think their back is "burned up", should be told that minor deviations are very common and often without any clinical significance, to restore patients' confidence in their own back and health. Changing patients' ideas is not always easy and may require extensive explanations and clarifications. The physical therapist should pay attention to patients doubts and feelings of anxiety by listening to the patient [78], and by giving realistic information or reassurance.

Coping. Points of attention in coping are the patients' behavioral repertoire and sense of effectance. More specifically, the physical therapist can ask the patient what he or she already has done to obtain relief. The answer reveals the kind of behavior the patient considers adequate and enables the physical therapist to adjust instructions and advice to already existing coping patterns or ideas, which are more likely to be sustained because they are independent of provider behavior $[19,34,72]$. For example, if a patient is used to take hot showers for pain relief, the therapist can suggest he or she takes the showers just before doing the exercises, because this may facilitate performance.

Another recommendation is teaching the patient to generalize desired behavior. This implies an activity at different levels. First and more traditional in patient education, the patient is supplied with information about the illness and how to cope with it. Apart from this the patient obtains information and guidelines at a meta-level, about the operating mechanisms behind the information itself. Using this knowledge the patient can then be stimulated to discover substituting behaviors containing the same mechanism, which perhaps fit better into present or future ways of living. For example, in training the patients the right way of lifting, they should understand why an object should be lifted as close to the body as possible. Then, patients will be stimulated to apply this principle and come up with simple solutions, tailored to their own situation.

Generalizing is particularly relevant to the type of problems physical therapy patients face. Daily fluctuations in symptom levels, as in rheumatoid arthritis, may even require that patients adjust their behavior accordingly [92,93]. Besides, it is virtually impossible to instruct patients in how to face every situation that may occur, because the variation in situations is enormous and often unforeseeable by the physical therapist.

Both using existing coping patterns and enabling the patient to discover and generalize adequate behavior may enhance patients' feelings of competence and selfeffectance, which is also the aim in the appraisal phase.

Appraisal. The physical therapist's contribution is teaching the patient how to interpret outcomes of compliance and explaining their relation to the coping behavior. It is important to help the patient in understanding that negative outcomes can be useful, rather than regarding them as signs of failure. Negative outcomes indicate that the specific coping behavior is inadequate or unsuitable for the patient's lifestyle and alternatives must be found. For example, when patients cannot afford to swim three times a week, one should encourage the patient to discover another way of exercising that suits them better instead of blaming them for noncompliance. In doing so feelings of inadequacy or failure can be avoided.

\section{Differences in curative and preventive measures}

The distinguishing factors between curative and preventive treatment noted before orientation in time and clear ability to evaluate success and failure - have consequences for the self-regulatory approach. Leventhal points to the tendency of patients (and perhaps also physical therapists) to 
think, and subsequently act, in terms of a disease model. This tendency may be responsible for failure to achieve long-term compliance with preventive measures [83]. In acute disease thinking, the presence of symptoms, the short-term nature of the illness and the possibility of curing the underlying disease process play an important part. These three aspects of the representation of the illness are all strongly related to curative treatment, but inversely related to preventive treatment. For preventive treatment to be successful, Leventhal argues, attention must be paid to changing such acute disease thinking into thinking in terms of maintaining health or avoiding risks [66]. So other targets must be found, for example, becoming a sportsman, feeling fit and healthy, looking supple and exercised, being autonomous and able to cope with life. The personal value of such targets may motivate the patient to comply.

At the same time this refers to a fundamental change from a medical model — with absence of disease as criterion for health - to a health model, where the capacity of the person to maintain his own health at an acceptable level is the ultimate goal [70]. The latter way of thinking can promote a patient's involvement in taking preventive measures to stay healthy.

\section{Conclusion}

The essence of our argument has been that different theoretical approaches are needed because compliance behaviors differ in nature. Analyzing short-term and long-term compliance one can see that there is a significant difference between the two as far as the degree of supervision is concerned. In the case of short-term compliance the patient is seen frequently by the physical therapist over a short period of time. After that period supervision lacks; patients must rely on their own recources to maintain the regimen. So, in physical therapy one can distinguish shortterm supervised compliance and long-term nonsupervised compliance.
A second distinction concerns the curative or preventive orientation of treatment. In curative treatment, compliance behavior is directed at recovery from illness and can be evaluated likewise, whereas in preventive treatment the goals are less tangible, thus making evaluation of the regimens success more difficult.

Because of these distinctions we argued that in short-term supervised compliance a behavioral approach offers the best perspective, whereas the self-regulation model is of greater use in achieving long-term nonsupervised compliance.

Choice of the behavioral approach rests on its known effectiveness in enhancing shortterm compliance and its easy applicability in the physical therapy setting. The selfregulation model is considered suitable for long-term compliance due to its emphasis on patients regulating their own behaviors without supervision.

The behavioral and the self-regulation models have similarities and differences. An important difference concerns the therapistpatient relationship. The behavioral approach implies a guidance-cooperation relationship between therapist and provider. The selfregulation model is characterized by a mutual-participation relationship [70,91]. The latter approach implicates a necessary change in professional attitude: from a guiding expert to a supporting one, who respects the patient's choices and allocates successes to the patient.

Besides these differences there are many similarities, becausc both models fit in the social learning theory framework. Social learning theory assumes that only individuals' perceptions and interpretations of events make them significant. In the behavioral approach this implies that patients must discover both cues and reinforcements meaningful to them and ways to integrate behavior in their daily routines. It is obvious in the selfregulation approach that the patient's perspective is of equal importance. 
Table 1. Implications for practice.

Short-term compliance

1. Cues:

2. Rewards:

3. Evaluation:

Long term compliance

1. Patients'

perception:

2. Coping:

3. Appraisal:

4. Emotions: together with the patients tailor exercises to patients' daily routines and find cues that can serve as reminders to exercise attend patients to rewarding effects like pain relief or progress and reward patients' efforts by giving them positive feedback

monitor patients' compliance continuously in an open atmosphere to solve problems or to adjust cues and rewards if necessary

check patients' ideas about health and illness and, if necessary, correct them analyze patients' existing coping patterns and if possible, utilize them; explain the principles underlying the desired behavior and teach patients to generalize these principles; motivate patients to discover adequate behaviors, tailored to their specific preference and lifestyle teach patients how to appraise outcomes: try to enhance patients' feelings of competence and self-efficacy by appraising outcomes in a positive way

pay careful attention to feelings and emotions that coping with illness brings along

5. Spread the treatment sessions over a relatively long period to allow patients to regulate and appraise their coping behavior by themselves

In deriving practical recommendations for physical therapists we based them on two considerations. First, the simplest and most powerful recommendations should be derived from the theories and, second, they should be performable with minimal extra effort. As a starting point the physical therapist should determine whether short-term or long-term compliance is the goal and subsequently derive from it a careful plan about the goal and strategy concerning the patient's compliance. Unplanned interventions are most likely to fail.

If short-term compliance is the purpose of treatment, all regular contacts can be utilized to apply a behavioral approach. The most powerful element appears to be reinforcement. A second element consists of discovering appropriate cues or situations for each individual patient taking into account the desired behavior. Applying these basic principles requires little extra skill or time. The effort will lie in making them a habit, which can be promoted by integrating their acquisition into physical therapists' vocational training.
Stimulating long-term compliance by applying the principles of the self-regulation model does require extra skills and effort from the physical therapist. To develop an intervention based on the self-regulation model, all the patient's ideas and perceptions about the illness should be explored first, in order to adjust the prescribed regimen to existing coping patterns. Secondly, it is important to teach patients to generalize underlying principles to enable them to choose and cope adequately in the future. The final point is teaching the patient how to appraise performances and outcomes in such a way that feelings of competence and self-efficacy are intensified.

Some final remarks should be made. The principle of this article is that compliance behaviors differ in nature and that, as a consequence, different theoretical approaches have to be indicated. We have made a general distinction in only two respects: short-term versus long-term compliance, and curative versus preventive measures. It seems worth while to continue this line of thought by making further specifications of compliance 
behaviors. For example, it could be significant to make further distinctions between high and low frequencies of desired behavior, or between regimens asking patients to unlearn bad habits versus learning new habits. In physical therapy it seems promising to continue analysis of compliance behaviors for different diseases or for different subgroups of patients. Such a further analysis of compliance behaviors may provide detailed guidelines for the practice.

The essence of this approach is that it should not be restricted to physical therapy, but that it can also be useful in other health care settings. Hopefully professionals in these fields will be inspired to undertake the same exercise for the types of compliance they encounter.

\section{References}

1 Campen C van, Sluijs EM: Patient compliance. A survey of reviews (1979-1989). Bibliography. Utrecht: Nivel, 1989.

2 Dishman RK, Dunn AL: Exercise adherence in children and youth: implications for adulthood. In: Dishman RK ed. Exercise Adherence, Its Impact on Public Health. Champaign, IL: Human Kinetic Books, 1988.

3 Haynes RB , Taylor DW, Sackett DL eds: Compliance in Health Care. Baltimore, MD: The John Hopkins University Press, 1979.

4 Cohen SJ: New metaphors for old problems. In: Cohen SJ ed. New Directions in Patient Compliance. Toronto: Lexington, 1979.

5 Cameron R, Allan Best J: Promoting adherence to health behavior change interventions: recent findings from behavioral research. Patient Educ Couns 1987; 10: 139-154.

6 Knapp DN: Behavioral management techniques and excrcise promotion. In: Dishman RK ed. Exercise Adherence, Its Impact on Public Health. Champaign, IL: Human Kinetic Books, 1988.

7 Dolan-Mullen PD, Green LW, Persinger GS: Clinical trials of patient education for chronic conditions: a comparative meta-analysis of intervention types. Prev Med 1985; 14: 753-781.

8 Leventhal $\mathrm{H}$ : The role of theory in the study of adherence to treatment and doctor-patient interactions. Med Care 1985; 23: 556-563.

9 Bartlett EE: Two year update. Patient Educ Couns 1987; 9: 1-3.

10 Kok G: Research in order to support health education in practice. In: First European Conference on Effectiveness of Health Education. Utrecht: Dutch Health Education Centre, 1989.

11 Becker MH: Patient adherence to prescribed therapies. Med Care 1985; 23: 539-555.

12 Oldridge NB: Compliance with exercise in cardiac rehabilitation. In: Dishman RK ed. Exercise Adherence, Its Impact on Public Health. Champaign, IL: Human Kinetic Books, 1988.

13 Green CA: What can patient health education coordinators learn from ten years of compliance research? Patient Educ Couns 1987; 10: 167-174.

14 Haynes RB, Wang E, Da Mota Gomes M: A critical review of interventions to improve compliance with prescribed medications. Patient Educ Couns 1987; 10: $155-166$.

15 Mazucca SA: Does patient education in chronic disease have therapeutic value ? J Chron Dis 1982; 35: 521-529.

16 Turk DC, Salovey P, Litt MD: Adherence, a cognitivebehavioral perspective. In: Gerber KE, Nehemkis AM eds. Compliance, the Dilemma of the Chronically Ill. New York: Springer, 1986.

17 Heiby EM, Carlson JG: The health compliance model. J Compliance Health Care 1986; 1: 135-152.

18 Dubbert PM, Martin JE, Epstein LH: Exercise. In: Holroyd KA, Greer TL eds. Self-Management of Chronic Disease. Handbook of Clinical Interventions and Research. Orlando, FL: Academic Press, 1986.

19 Ice R: Long-term compliance. Phys Ther 1985; 65: 1832-1839.

20 Lafreniere JG: The Low Back Patient, Procedures for Treatment by Physical Therapy. New York: Masson, 1979.

21 Mayo NE: Patient compliance: practical implications for physical therapists. Phys Ther 1978; 58: 1083-1090.

22 Kerssens JJ, Groenewegen PP: Referrals to Physiotherapy: the Relation Between the Number of Referrals, the Indication for Referral and the Inclination to Refer. Utrecht: NIPC, 1989.

23 Min WVC van: Notitie ontwikkeling van de fysiotherapeutische hulpverlening. 's Gravenhage, SDLL Uitgeverij, 1989.

24 Groenewegen PP: Fysiotherapeut. In: Sluijs EM, Dopheide JP, Zee J van der eds. Overzichtsstudic onderzoek eerstelijn. Utrecht: Nivel, 1985.

25 Hayne CR: The preventive role of physiotherapy in the National Health Service and Industry. Physiotherapy 1988; 74: $2-3$.

26 Knibbe JJ: Fysiotherapic en sccundaire preventie van lage rugklachten. Literatuurstudie naar mogelijkheden en beperkingen. Ned Tijdschr Fysiother 1987; 97: 175-183.

27 Bertels M, Brummelen L ten, Dijkum C van, et al: Tijd voor kwaliteit: evaluatie onderzoek fysiotherapie in gezondheidscentra in Amstcrdam. Amsterdam: Stichting Universitair Instituut voor Sociaal Wetenschappelijk Onderzoek/Onderzoeksplatform in de Eerstelijns Dienstverlening in Amsterdam, 1985. 
28 Belcon MC, Haynes RB, Tugwell P: A critical review of compliance studies in rheumatoid arthritis. Arthritis Rheum 1984; 27: 1227-1233.

29 Evans C, Gilbert JR, Taylor W, Hildebrand A: A randomized controlled trial of flexion exercises, education, and bed rest for patients with acute low back pain. Physiother Can 1987; 39: 96-101.

30 Lindequist S, Lundberg B, Wikmark R, Bergstad B, Loof $\mathrm{G}$, Ottermark $A C$ : Information and regime at low back pain. Scand J Rehab Med 1984; 16: 113-116.

31 Mellin G, Järvikoski A, Verkasalo $\mathbf{M}$ : Treatment of patients with chronic low back pain. Comparison between rehabilitation centre and outpatient care. Scand J Rehab Med 1984; 16: 77-84.

32 Snook SH: Comparison of different approaches for the prevention of low back pain. Ergonomic interventions to prevent musculosceletal injuries in industry. In: Industrial Hygiene Science Series II Michigan: Lewis, 1987, pp. $57-72$.

33 Dishman RK: Compliance/adherence in health-related exercise. Health Psychol 1982; 3: 237-267.

34 Sikorski JM: A rationalized approach to physiotherapy for low back pain. Spine 1985; 10: 571-579.

35 Deyo RA, Tsui-Wuu YJ: Descriptive epidemiology of low-back pain and its related medical care in the United States. Spine 1987; 12: 264-268.

36 Feinberg J: The effect of patient-practitioner interaction on compliance: a review of the literature and application in rheumatoid arthritis. Patient Educ Couns 1988; 11: $171-187$.

37 Ferguson K. Bole GG: Family support, health beliefs, and therapeutic compliance in patients with rheumatoid arthritis. Patient Couns Health Educ 1979; 1: 101-105.

38 Lankhorst GJ, Stadt RJ van de, Vogelaar TW, Korst JK van der, Pravo AJH: The effect of the Swedish back school in chronic idiopathic low back pain. Scand J Rehab Med 1983; 15: 141-145.

39 Spelman MR: Back pain: how health education affects patient compliance with treatment. Occup Health Nurs 1984; 32: 649-651.

40 Berwick DM, Budman S, Feldstein M: No clinical effects of back schools in an HMO. A randomized prospective trial. Spine 1989; 14: 338-344.

41 Oldridge NB, Jones NL: Preventive use of exercise rehabilitation after myocardial infarction. In: Astrand PO, Grimby G eds. Physical Activity in Health and Disease. Acta Medica Scandinavica Symp. Series no. 2. Stockholm: Almquist and Wiksell, 1986.

42 Treusch JV, Krusen FH: Physical therapy applied at home for arthritis. Arch Intern Med 1943; 72: 231-238.

43 Beekman CE, Axtell L: Ambulation, activity level and pain, outcomes of a program for spinal pain. Phys Ther 1985; 65: 1649_ 1657.

44 Deyo RA: Compliance with therapeutic regimens in arthritis: issues, current status, and a future agenda. Semin Arthritis Rheum 1982; 12: 233-244.

45 Sluijs EM: Assessment of patient education in physical therapy. Phys Ther, submitted.
46 Gillum RF, Barsky AJ: Diagnosis and management of patient non-compliance. JAMA 1974; 228: 1563-1567.

47 Czerniawski L: Exercise therapy: the role of physical therapy. In: Stanton-Hicks M, Boas RA eds. Chronic Low Back Pain. New York: Raven Press, 1982.

48 Huhn RR, Volski RV: Primary prevention programs for business industry. Role of physical therapists. Phys Ther 1985; 65: $1840-1844$.

49 Leathly M: Physiotherapists and health education. Report of a survey. Physiotherapy 1988; 74: $218-220$.

50 May BJ: Teaching. A skill in clinical practice. Phys Ther 1983; 63: $1627-1633$.

51 Norton S: Support for physiotherapists in health education. Physiotherapy 1986; 72: 5-7.

52 Dishman RK: Epilogue and future directions. In: Dishman RK ed. Exercise Adherence, Its Impact on Public Health. Champaign, IL: Human Kinetic Books, 1988.

53 Haynes RB: Determinants of compliance: the disease and the mechanism of treatment. In: Haynes RB, Taylor DW, Sackett DL eds. Compliance in Health Care. Baltimore, MD: The John Hopkins University Press, 1979.

54 Southam MA, Dunbar J: Facilitating patient compliance with medical interventions. In: Holroyd KA, Greer TL eds. Self-Management of Chronic Disease. Handbook of Clinical Interventions and Research. Orlando, FL: Academic Press, 1986.

55 Hough A: Communication in health care. Physiotherapy 1987; 73: $56-59$.

56 Lyne PA: The professions allied to medicine, their potential contribution to health education. Physiotherapy 1986; 72: $8-10$.

57 Saunders C, Maxwell M: The case for counseling in physiotherapy. Physiotherapy 1988; 74: 592-595.

58 Curfs EC, Groenewegen PP: Physiotherapy in the Netherlands: an overview. Physiother Pract 1986; 2: $132-137$.

59 Knibbe JJ: Integration of secondary prevention of low back pain in physical therapy treatment, a literature review. Profession in action, 100 years of physiotherapy in Holland, June. 1989, The Hague.

60 Kok G: Health motivation: health education from a social psychological point of view. In: Maes S, Spielberger CD, Defares PB, Sarason IG eds. Topics in Health Psychology. New York: Wiley, 1988.

61 Posavac EJ: Evaluations of patient education programs: a meta-analysis. Eval Health Professions 1980; 3: 47-62.

62 Karoly P: Operant methods. In: Kanfer FH, Goldstein AP eds. Helping People Change, a Textbook of Methods II. New York: Pergamon Press, 1980.

63 Levy RL: Social support and compliance: a selective review and critique of treatment integrity and outcome measurement. Soc Sci Med 1983; 17: 1329-1338.

64 Dunbar JM, Marshall GD, Hovell MF: Behavioral strategies for improving compliance. In: Haynes RB, Taylor DW, Sackett DL eds. Compliance in Health Care. Baltimore, MD: The John Hopkins University Press, 1979. 
65 Linden $H$ van der: Fysiotherapie en patientenvoorlichting. Ned Tijdschr Fysiother 1987; 97: 106-112.

66 Leventhal $H$, Cameron $L$ : Behavioral theories and the problem of compliance. Patient Educ Couns 1987; 10: $117-138$

67 Tobin DL, Reynolds RVC, Holroyd KA, Greer TL: Selfmanagement and social learning theory. In: Holroyd KA, Greer TL eds. Self-Management of Chronic Disease. Handbook of Clinical Interventions and Research. Orlando, FL: Academic Press, 1986.

68 Martin JE, Dubbert PM: Exercise applications and promotion in behavioral medicine. Current status and future directions. J Consult Clin Psychol 1982; 50: 1004-1017.

69 Sackett DL: A compliance practicum for the busy practitioner. In: Haynes RB, Taylor DW, Sackett DL eds. Compliance in Health Care. Baltimore, MD: The John Hopkins University Press, 1979.

70 Bartlett EE: The medical and educational models of health care under prospective pricing. Patient Educ Couns 1984; 2: $57-61$.

71 Green LW: Educational strategies to improve compliance with therapeutic and preventive regimens: the recent evidence. In: Haynes RB, Taylor DW, Sackett DL eds. Compliance in Health Care. Baltimore, MD: John Hopkins University Press, 1979.

72 Boczkowski JA, Zeichner A: Medication compliance and the elderly. Clin Gerontol 1985; 4: 3-15.

73 Kanters HW: Effectiviteit van patientenvoorlichting: een literatuuronderzoek. Landelijk Centrum Dienstverlening G.V.O. Utrecht, 1986.

74 Cairns D, Thomas L, Mooney V, Blair Pace J: A comprehensive treatment approach to chronic low back pain. Pain 1976; 2: 301-308.

75 Rand PH: Evaluation of patient education programs. Phys Ther 1978; 58: 851-856.

76 Bartlett EE: Rehavioral diagnosis: a practical approach to patient education. Patient Couns Health Educ 1982; 4: $29-35$.

77 Hanson RW: Physician-patient communication and compliance. In: Gerber KE, Nehemkis AM eds. Compliance. The Dilemma of the Chronically Ill. New York: Springer, 1986.

78 Croft JJ: Interviewing in physical therapy. Phys Ther 1980; 60: 1033-1036.

79 Ley Ph: Giving information to patients. In: Eiser JR ed. Social Psychology and Behavioral Medicine. New York: Wiley, 1982.

80 Wagstaff GF: A small dose of commonsensecommunication, persuasion and physiotherapy. Physiotherapy $1982 ; 68 ; 327-329$.
81 Haynes RB: Patient compliance then and now. Patient Educ Couns 1987; 10: 103-105.

82 Snook SH: Approaches to the control of back pain in industry: job design, job placement and education/training. Occupational Medicine: State of the Art Reviews 1988; 3 : $45-61$.

83 Leventhal H, Zimmerman R, Gutmann M: Compliance: A self-regulation perspective. In: Doyle Gentry W ed. Handbook of Behavioral Medicine. New York: The Guilford Press, 1984

84 Janz NK, Becker MH: The Health Belief Model: a decade later. Health Educ Q 1984; 11: 1-47.

85 Bandura A: Self-efficacy. Toward a unifying theory of behavior change. Psychol Kev 1977; 84: 191-215.

86 Simonds SK: Individual health counseling and education: emerging directions from current theory, research, and practice. Patient Couns Health Educ 1983; 4: 175-181.

87 Gerber KE: Compliance in the chronically ill: an introduction to the problem. In: Gerber KE, Nehemkis AM eds. Compliance. The Dilemma of the Chronically Ill. New York: Springer, 1986.

88 Trostle JA: Medical compliance as an ideology. Soc Sci Med 1988; 27: 1299-1308.

89 Steele DJ, Blackwell B, Gutmann MC, Jackson TC: The activated patient: dogma, dream, or desideratum? Beyond advocacy: a review of the active patient concept. Patient Educ Couns 1987; 10: 3-23.

90 Stone GC: Patient compliance and the role of the expert. J Social Issues 1979; 35: 35-59.

91 Szazz TS, Hollender MH: A contribution to the philosophy of medicine: the basic models of the doctorpatient relationship. In: Stockle JD ed. Encounters Between Patients and Doctors. Massachusetts, MA: MIT Press, 1987.

92 Mahowald ML, Steveken ME, Young M, Ytterberg SR: The Minnesota Arthritis-Training Program: emphasis on self-management, not compliance. Patient Educ Couns 1988; 11: $235-241$.

93 Lorig K, Konkol L, Gonzalez V: Arthritis patient education: a review of the literature. Patient Educ Couns 1987; 10: $207-257$.

\section{Correspondence to:}

E.M. Sluijs

Netherlands Institute of Primary Health Care

PO Box 1568

3500 BN Utrecht

The Netherlands 